\title{
ACTIVIDAD CITOTÓXICA DE LA FRACCIÓN CLOROFÓRMICA DE Piper aduncum Y SU EFECTO EN EL CICLO CELULAR EN LÍNEAS CELULARES DE CÁNCER GÁSTRICO
}

\author{
Ana Mayanga-Herrera@1;,2,a, Salyoc Tapia-Rojas (101,2,b, Alejandro Fukusaki-Yoshizawa ${ }^{2,3, c,}$, \\ Álvaro Marcelo-Rodríguez (1) 2,3,d, José Amiel-Pérez (10) 2,e \\ ${ }^{1}$ Laboratorio de Cultivo Celular e Inmunología, Universidad Científica del Sur, Lima, Perú. \\ 2 Instituto de Medicina Regenerativa, Universidad Científica del Sur, Lima, Perú. \\ 3 Laboratorio de Química y Bioquímica de los Productos Naturales, Universidad Científica del Sur, Lima, Perú. \\ a Bióloga genetista biotecnóloga, maestra en Ciencias con especialidad en Biotecnología; ${ }^{b}$ bachiller en Genética y Biotecnología; \\ c químico, magíster scientiae en Tecnología de Alimentos; ${ }^{\mathrm{d}}$ biólogo, doctor en Bioquímica; ${ }^{\mathrm{e}}$ químico farmacéutico, doctor en \\ Farmacia y Bioquímica.
}

\section{RESUMEN}

Objetivos: Evaluar la actividad citotóxica de la fracción clorofórmica del extracto metanólico de Piper aduncum (PAMoCl) y su efecto en el ciclo celular en dos líneas celulares de cáncer gástrico: AGS y KATO III. Materiales y métodos: El efecto citotóxico de PAMoCl se evaluó en las líneas celulares: AGS y KATO III. Se probaron concentraciones de PAMoCl: 1,$25 ; 2,5 ; 5 ; 10 ; 20 ; 40 ; 80$ y $160 \mu \mathrm{g} / \mathrm{mL}$. Para evaluar la viabilidad celular se usó el reactivo resazurina. En el ensayo de ciclo celular las células fueron tratadas con $19,62 \mu \mathrm{g} / \mathrm{mL}$ y $39,23 \mu \mathrm{g} / \mathrm{mL}$ de PAMoCl para AGS, así como $87,49 \mu \mathrm{g} / \mathrm{mL}$ y $160 \mu \mathrm{g} / \mathrm{mL}$ para KATO III. Después de 24 horas ambas líneas celulares fueron analizadas por citometría de flujo. Resultados: PAMoCl mostró actividad citotóxica con una inhibición del crecimiento celular en un $50 \%\left(\mathrm{IC}_{50}\right)$ de $39,23 \mu \mathrm{g} / \mathrm{mL}$ y $87,49 \mu \mathrm{g} / \mathrm{mL}$ a las 24 horas y un $\mathrm{IC}_{50}$ de $49,47 \mu \mathrm{g} / \mathrm{mL}$ y $64,68 \mu \mathrm{g} / \mathrm{mL}$ a las 48 horas frente a las líneas celulares AGS y KATO III, respectivamente. Además, se observó que PAMoCl tiene efecto a nivel del ciclo celular: provoca una acumulación de células en la fase G2/M. Conclusiones: PAMoCl contiene metabolitos secundarios con actividad citotóxica que tienen efecto en la fase G2/M del ciclo celular, en dos líneas celulares de cáncer gástrico tanto primario como metastásico. Los resultados de este estudio permitirán profundizar en la búsqueda de principios activos presentes en PAMoCl que tengan mayor eficacia en la eliminación de células de cáncer gástrico, pero con menor toxicidad en células sanas.

Palabras clave: Cáncer Gástrico; Citotoxicidad; Ciclo Celular; Cloroformo; Metástasis (Fuente: DeCs BIREME).

\section{CYTOTOXIC ACTIVITY OF THE CHLOROFORM FRACTION OF Piper aduncum AND ITS EFFECT ON THE CELL CYCLE IN GASTRIC CANCER CELL LINES}

\begin{abstract}
Citar como: Mayanga-Herrera A, Tapia-Rojas S, Fukusaki-Yoshizawa A, Marcelo-Rodríguez A, Amiel-Pérez J. Actividad citotóxica de la fracción clorofórmica de Piper aduncum y su efecto en el ciclo celular en líneas celulares de cáncer gástrico. Rev Peru Med Exp Salud Publica. 2020;37(3):4717. doi: https://doi.org/10.17843/ rpmesp.2020.373.5157
\end{abstract}

Correspondencia: Ana MayangaHerrera; amayanga@cientifica.edu.pe

Recibido: $24 / 01 / 2020$ Aprobado: $21 / 05 / 2020$

En línea: 06/07/2020

\begin{abstract}
Objectives: To evaluate the cytotoxic activity of the chloroform fraction of the Piper aduncum methanolic extract (PAMoCl) and its effect on the cell cycle in two gastric cancer cell lines: AGS and KATO III. Materials and methods: The cytotoxic effect of PAMoCl was evaluated in cell lines AGS and KATO III. The following PAMoCl concentrations were tested, $1.25,2.5,5,10,20,40,80$ and $160 \mu \mathrm{g} / \mathrm{mL}$. Resazurine was used to evaluate cell viability. In the cell cycle assay, the cells were treated with $19.62 \mu \mathrm{g} / \mathrm{mL}$ and 39.23 $\mu \mathrm{g} / \mathrm{mL}$ of PAMoCl for AGS as well as $87.49 \mu \mathrm{g} / \mathrm{mL}$ and $160 \mu \mathrm{g} / \mathrm{mL}$ for KATO III. After 24 hours both cell lines were analyzed by flow cytometry. Results: PAMoCl showed cytotoxic activity, inhibiting cell growth by $50 \%$. It presented a $\left(\mathrm{IC}_{50}\right)$ of $39.23 \mu \mathrm{g} / \mathrm{mL}$ and $87.49 \mu \mathrm{g} / \mathrm{mL}$ at 24 hours and a $\left(\mathrm{IC}_{50}\right)$ of $49.47 \mu \mathrm{g} / \mathrm{mL}$ and $64.68 \mu \mathrm{g} / \mathrm{mL}$ at 48 hours against AGS and KATO III cell lines, respectively. In addition, it was observed that PAMoCl has an effect on the cell cycle, it causes an accumulation of cells in the G2/M phase. Conclusions: PAMoCl contains secondary metabolites with cytotoxic activity that have an effect on the G2/M phase of the cell cycle, in two gastric cancer cell lines, both primary and metastatic. The results of this study will allow us to deepen the search for more effective active ingredients found in $\mathrm{PAMoCl}$ for eliminating gastric cancer cells, but with less toxicity for healthy cells.
\end{abstract}

Keywords: Gastric Cancer, Cytotoxicity, Cell Cycle, Chloroform, Metastasis (Source: MeSH NLM). 


\section{INTRODUCCIÓN}

El cáncer gástrico es la tercera causa más común de muerte por cáncer en todo el mundo ${ }^{(1)}$ y la primera en el Perú ${ }^{(2)}$. Por lo general, se detecta en etapas avanzadas donde es casi imposible aplicar un tratamiento efectivo. Dado que los efectos secundarios de la quimioterapia son muy tóxicos, se ha vuelto urgente buscar nuevas fuentes de medicamentos que muestren mayor especificidad frente a las células cancerosas, mayor eficacia y menos efectos secundarios.

Las plantas medicinales se están estudiando como fuente de nuevos productos quimioterapéuticos. Hoy en día, alrededor del $60 \%$ de los medicamentos que se utilizan para el tratamiento del cáncer se derivan de fuentes vegetales; por ejemplo: paclitaxel, obtenido inicialmente de Taxus brevifolia Nutt. ${ }^{(3)}$; camptotecina, de Captotheca acuminata ${ }^{(4)}$; etopósido, de especies de Podophyllum ${ }^{(5)}$; vincristina, de Catharanthus roseus ${ }^{(6)}$; colchicina, de Colchicum autumnale ${ }^{(7)}$.

El género Piper consta de 700 especies que crecen en diversas partes del mundo y sus especies tienen varios efectos positivos en la salud, como en la protección gastrointestinal y hepática ${ }^{(8)}$. Además, muchas especies del género Piper han demostrado tener citotoxicidad frente a las líneas celulares de cáncer de mama, cáncer de cuello uterino, cáncer de próstata, cáncer de ovario, páncreas, hígado, colon entre otras ${ }^{(9)}$.

Se ha reportado que el extracto etanólico de la especie de $P i$ per aduncum mostró actividad citotóxica frente a células MCF7 (cáncer de mama) y NCI-H460 (carcinoma pulmonar) ${ }^{(10)}$. Sin embargo, aún no se ha informado el efecto de la fracción clorofórmica del extracto metanólico de Piper aduncum (PA$\mathrm{MoCl}$ ) en las células de cáncer gástrico. Por lo tanto, el objetivo de este estudio fue evaluar la actividad citotóxica de la PAMoCl y su efecto en el ciclo celular en dos líneas celulares de cáncer gástrico: AGS y KATO III.

\section{MATERIALES Y MÉTODOS}

\section{Elaboración de la fracción clorofórmica de Piper aduncum}

Las hojas de Piper aduncum fueron colectadas de la zona del bajo Kimiri, distrito de la Merced, provincia de Chanchamayo, departamento de Junín, en las coordenadas $11^{\circ} 02^{\prime} 16.5^{\prime \prime} \mathrm{S} 75^{\circ} 18^{\prime} 54.0^{\prime \prime} \mathrm{W}$. Se colectaron hojas que se encontraron de manera silvestre, y de estas una muestra fue identificada taxonómicamente como Piper aduncum L. por el museo de historia natural de la Universidad Nacional Mayor de San Marcos. Para la elaboración del extracto metanólico (PAMo) y la fracción clorofórmica (PAMoCl) de Piper aduncum, se usaron protocolos estandarizados en el laboratorio de Química y Bioquímica de los Productos Naturales de la Universidad Científica del Sur ${ }^{(11)}$.

\section{MENSAJES CLAVE}

Motivación para realizar el estudio: Debido a la alta tasa de mortalidad del cáncer gástrico en el Perú es importante conocer si nuestra biodiversidad puede albergar metabolitos con actividad citotóxica frente a este tipo de cáncer.

Principales hallazgos: Se encontró que la fracción clorofórmica de Piper aduncum tiene actividad citotóxica, lo que causa la detención en la fase G2/M en dos líneas celulares de cáncer gástrico, siendo una de ellas la línea celular metastásica.

Implicancias: Debido a que la fracción clorofórmica tiene citotoxicidad frente a una línea celular metastásica de cáncer gástrico, la identificación de los metabolitos responsables de esta actividad serían importantes para los nuevos tratamientos frente a el cáncer gástrico en metástasis.

Brevemente, las hojas fueron limpiadas y secadas a $40{ }^{\circ} \mathrm{C}$ durante dos días, posteriormente trituradas y tamizadas con una malla de $1 \mathrm{~mm}$. Luego se pesaron $70 \mathrm{~g}$ de hojas en polvo, se adicionaron $300 \mathrm{~mL}$ de metanol y se filtró a través de un papel filtro Whatman n. ${ }^{\circ} 1$. Este procedimiento se repitió 8 veces, de las cuales las 3 últimas se sonicaron durante 2 horas. Todo el PAMo fue filtrado usando una membrana de 0,44 $\mu \mathrm{m}$. Para obtener la fracción clorofórmica de Piper aduncum (PAMoCl), el PAMo se concentró a $200 \mathrm{~mL}$ y se sometió a extracción con cloroformo agregando $300 \mathrm{~mL}$ de cloroformo en un tubo de decantación de 1 L. Esta operación se repitió 8 veces. La PAMoCl se concentró a presión reducida con un rotavapor. PAMo y $\mathrm{PAMoCl}$ fueron analizados por cromatografía en capa fina (TLC) usando gel de sílice 60 para la fase estacionaria y benceno-acetona 8:1 como fase móvil, se reveló con yodo y luz ultravioleta (UV) ${ }^{(12)}$. Se realizaron ensayos complementarios para identificar grupos químicos tanto para PAMo como para PAMoCl de acuerdo los protocolos descritos por Lock ${ }^{(13)}$. Por último, la PAMoCl se llevó a una concentración de $32 \mathrm{mg} / \mathrm{mL}$ en dimetilsulfóxido (DMSO) y se almacenó a $-80{ }^{\circ} \mathrm{C}$ para su posterior uso. Los solventes usados son de grado analítico y se adquirieron de la empresa Merck.

\section{Cultivo de líneas celulares}

Las líneas celulares de cáncer gástrico humano AGS (primario) y KATO III (metastásico) se adquirieron de la Colección Europea de Cultivos Celulares Autenticados (ECACC 89090402 y 86093004). La línea celular 293T (ATCC® CRL-3216TM) se obtuvo del laboratorio de Genética Molecular de la Universidad Científica del Sur.

Las células AGS y 293T fueron cultivadas con DMEM-F12 (Biowest) suplementado con suero fetal bovino al 10\% y so- 
lución antibiótica-antimicótica al 1\% (DMEM-F12 completo). Mientras que la línea celular KATO III se cultivó con medio RPMI (Biowest) suplementado con suero fetal bovino al 20\% y solución antibiótica-antimicótica al 1\% (Biowest). Todas las células fueron incubadas a $37^{\circ} \mathrm{C}$ con $5 \%$ de $\mathrm{CO}_{2} \mathrm{y}$ subcultivadas cuando la confluencia fue del 70-80\%.

\section{Ensayo de viabilidad celular}

El ensayo de viabilidad celular se realizó como se describió previamente ${ }^{(14)}$. Las células AGS y $293 \mathrm{~T}$ fueron contadas usando una cámara de Neubauer y se sembraron $5 \times 10^{3}$ células/pocillo en placas de 96 pocillos. Mientras que las células KATO III se sembraron en una cantidad de $10^{4}$ células/ pocillo. Todas las células se incubaron durante 12 horas, luego se trataron con $1,25 \mu \mathrm{g} / \mathrm{mL}, 2,5 \mu \mathrm{g} / \mathrm{mL}, 5 \mu \mathrm{g} / \mathrm{mL}, 10 \mu \mathrm{g} /$ $\mathrm{mL}, 20 \mu \mathrm{g} / \mathrm{mL}, 40 \mu \mathrm{g} / \mathrm{mL}, 80 \mu \mathrm{g} / \mathrm{mL}$ y $160 \mu \mathrm{g} / \mathrm{mL}$ de PAMoCl, y nuevamente se incubaron durante 24 y 48 horas. Además, se incluyó un grupo control que tiene el vehículo (DMSO al $0,5 \%)$ pero no el PAMoCl. Para el análisis de la viabilidad celular, se añadieron $20 \mu \mathrm{L}$ de resazurina $(0,15 \mathrm{mg} / \mathrm{mL})$ a cada pocillo y se incubó durante 3 horas. Por último, las placas de 96 pocillos fueron leídas con un lector de placas multimodal Synergy LX (Biotek) por espectrofotometría a las longitudes de onda de $570 \mathrm{~nm}$ y $600 \mathrm{~nm}$. Se realizó el cálculo de la concentración de $\mathrm{PAMoCl}$ que ocasiona la inhibición del crecimiento celular en un $50 \%\left(\mathrm{IC}_{50}\right)$ con respecto al crecimiento del grupo control.

\section{Observación de la morfología celular}

Los cambios en la morfología celular después de la incubación de las células AGS, KATO III y 293T con PAMoCl fueron observados y fotografiados en un microscopio invertido de contraste de fases (Nikon Eclipse TI) después de 24 y 48 horas.

\section{Evaluación del ciclo celular por citometría de flujo}

Para la evaluación del efecto de $\mathrm{PAMoCl}$ en el ciclo celular se siguió el protocolo de Darzynkiewicz et al. ${ }^{(15)}$ con ligeras modificaciones. Se sembraron 350000 y 500000 células en placas petri de $100 \times 15 \mathrm{~mm}$ con medios DMEM-F12 y RPMI, ambos completos de las líneas celulares AGS y KATO III, respectivamente. Después de 24 horas, el medio de cultivo fue reemplazado con nuevo medio DMEM-F12 y RPMI completo que contenían el PAMoCl a las concentraciones de 19,62 y 39,23 $\mu \mathrm{g} / \mathrm{mL}$ para las células AGS y 87,49 y $160 \mu \mathrm{g} / \mathrm{mL}$ para las células KATO III; estas concentraciones se obtuvieron del ensayo de viabilidad celular. Todas las placas fueron incubadas por 24 horas a $37^{\circ} \mathrm{C}$ y $5 \%$ de $\mathrm{CO}_{2}$. Después de transcurridas 24 horas, las placas fueron lavadas dos veces con Buffer Fosfato Salino (PBS) $1 \mathrm{X}$ y tripsinizadas durante 5 minutos. Las células resuspendidas fueron colectadas por centrifugación y fijadas con etanol frío al 70\%. Luego se incubaron a $4{ }^{\circ} \mathrm{C}$ durante 30 minutos y una vez transcurrido este tiempo, las células fueron teñidas con una solución de Yoduro de Propidio $(50 \mu \mathrm{g} / \mathrm{mL})$ y RNasa $(100 \mu \mathrm{g} / \mathrm{mL})$ por 30 minutos adicionales e inmediatamente analizadas en el citómetro de flujo Guava EasyCyte (Merck).

\section{Análisis de los datos}

Los datos de absorbancia obtenidos del ensayo de viabilidad celular fueron exportados a un archivo de Microsoft Excel y expresadas en porcentajes con respecto al grupo control. Para la relación dosis-respuesta y el cálculo de los valores de $\mathrm{IC}_{50}$, se usó un modelo de regresión no lineal. Las diferencias significativas entre grupos fueron comparados usando la prueba de ANOVA de una vía con la prueba de Tukey, como prueba post hoc $(\mathrm{p}<0,05)$, usando el programa GraphPad Prism. Los resultados de ciclo celular fueron analizados usando el programa FCS 7 Express (DeNovo solutions). Los datos analizados son el resultado de tres experimentos independientes.

\section{RESULTADOS}

La presencia de metabolitos en PAMo y PAMoCl fue evidenciada por TLC (Figura 1) y la identificación de los grupos químicos se detallan en la Tabla 1 .
Luz visible
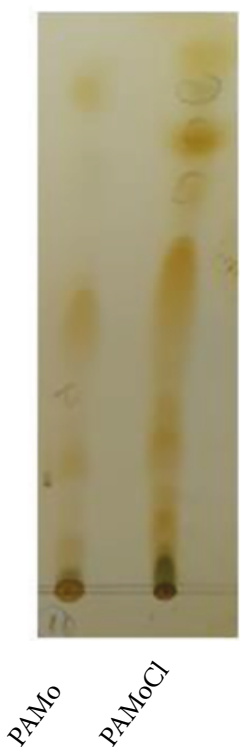

UV $366 \mathrm{~nm}$
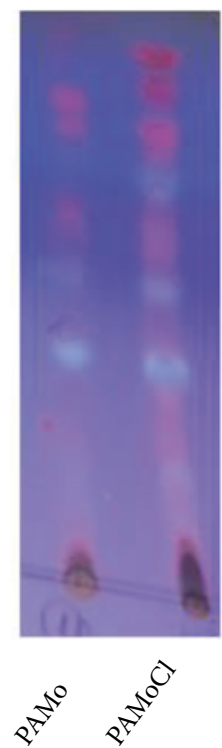

UV $254 \mathrm{~nm}$
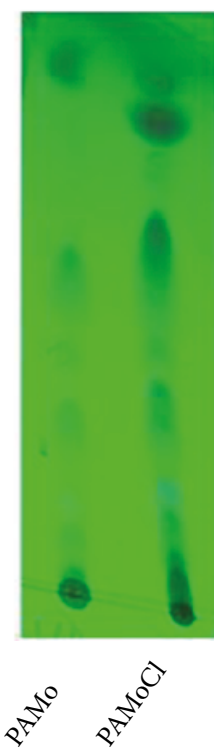

PAMoCl: fracción clorofórmica del extracto metanólico de Piper aduncum; PAMo: extracto metanólico de Piper aduncum

Figura 1. Perfil de cromatografía en capa fina del extracto metanólico de Piper aduncum y de la fracción clorofórmica del extracto metanólico de Piper aduncum revelados con yodo (luz visible) y luz UV. Fase móvil: benceno-acetona 8:1. Fase estacionaria: gel de sílice 60 
Tabla 1. Grupos de metabolitos presentes en el extracto metanólico de Piper aduncum y en su fracción clorofórmica

\begin{tabular}{lccc}
\hline Grupo de metabolito & Reacción & PAMo & PAMoCl \\
\hline Fenólicos & $\mathrm{FeCl}_{3}$ & Positivo & Positivo \\
Flavonoides & Shinoda & Positivo & Positivo \\
Antocianinas & Rosenhein & Positivo & Positivo \\
$\begin{array}{l}\text { Triterpenoides y } \\
\text { esteroides }\end{array}$ & $\begin{array}{c}\text { Lieberman- } \\
\text { Buchard }\end{array}$ & Positivo & Positivo \\
\hline
\end{tabular}

PAMoCl: fracción clorofórmica del extracto metanólico de Piper aduncum, PAMo: extracto metanólico de Piper aduncum

\section{Efecto de la fracción clorofórmica del extracto metanólico de Piper aduncum sobre la viabilidad celular}

Del ensayo de viabilidad celular se observó actividad citotóxica de PAMoCl en todas las líneas celulares evaluadas, obteniéndose los siguientes resultados de $\mathrm{IC}_{50}$ para las 24 horas: $39,23 \mu \mathrm{g} / \mathrm{mL} ; 87,49 \mu \mathrm{g} / \mathrm{mL}$ y $74,10 \mu \mathrm{g} / \mathrm{mL}$ y a las 48 horas $49,47 \mu \mathrm{g} / \mathrm{mL} ; 64,68 \mu \mathrm{g} / \mathrm{mL}$ y $101,8 \mu \mathrm{g} / \mathrm{mL}$ para las líneas celulares AGS, KATO III y 293T, respectivamente (Figura 2). A las 48 horas, se observó que los valores de $\mathrm{IC}_{50}$ de $\mathrm{PAMoCl}$ son significativamente menores para las líneas AGS y KATO III comparados con el de la línea 293T (control de citotoxicidad) con valores de $\mathrm{p}<0,01$ y $\mathrm{p}<0,05$, respectivamente (Figura 3).

\section{Observación de la morfología celular}

Se observaron cambios de una manera dependiente de la dosis de PAMoCl en la morfología de las células AGS, KATO III y 293T (Figura 4). En la línea celular AGS, después del tratamiento de 24 horas con $\mathrm{PAMoCl}$, se observó que a partir de $20 \mu \mathrm{g} / \mathrm{mL}$ las células empezaban a contraerse y otras a resuspenderse. En concentraciones mayores, $80 \mu \mathrm{g} / \mathrm{mL}$ y
$160 \mu \mathrm{g} / \mathrm{mL}$, se observó mayor cantidad de fragmentos celulares, pocas células resuspendidas y ninguna adherida. A las 48 horas el efecto observado fue similar. En la línea celular KATO III, se empiezan a observar células muertas (Figura 4) a partir de $80 \mu \mathrm{g} / \mathrm{mL}$ tanto para las 24 y 48 horas. En la línea celular 293T, después del tratamiento de 24 horas con PAMoCl, se observó que a partir de $80 \mu \mathrm{g} / \mathrm{mL}$ las células empezaban a contraerse y a $160 \mu \mathrm{g} / \mathrm{mL}$ se observó mayor cantidad de células contraídas y resuspendidas, sin embargo, aún podían observarse células adheridas a la placa de cultivo. A las 48 horas el efecto observado fue similar.

\section{Efecto en el ciclo celular}

Los resultados mostraron efecto en el ciclo celular sobre las líneas de cáncer gástrico. En las células AGS, el porcentaje de células en fase G2/M fue 31,8\%; 44,1\% y 52,7\% para las concentraciones de $0 \mu \mathrm{g} / \mathrm{mL} ; 19,62 \mu \mathrm{g} / \mathrm{mL}$ y $39,23 \mu \mathrm{g} / \mathrm{mL}$ de PA$\mathrm{MoCl}$, respectivamente (Figura $5 \mathrm{~A}-\mathrm{C}$ ). En las células KATO III, el porcentaje de células en fase G2/M fue: 30,9\%; 29,3\% y $49,0 \%$ para las concentraciones de $0 \mu \mathrm{g} / \mathrm{mL} ; 87,49 \mu \mathrm{g} / \mathrm{mL}$ y $160 \mu \mathrm{g} / \mathrm{mL}$ de PAMoCl, respectivamente (Figura $5 \mathrm{D}-\mathrm{F}$ ).

\section{DISCUSIÓN}

Este es el primer estudio reportado en el que se demostró la actividad citotóxica de PAMoCl y su efecto en el ciclo celular en dos líneas celulares de cáncer gástrico: AGS y KATO III.

Los valores de $\mathrm{IC}_{50}$ en este estudio para ambas líneas son menores con respecto a los valores reportados por Herrera et al. para el extracto etanólico de $P$. aduncum en las líneas celulares MCF-7, HT-29, K-562 y H-460 ${ }^{(10)}$. Es importante mencionar que los valores de $\mathrm{IC}_{50}$ de este estudio para las líneas AGS y KATO III son significativamente menores que el de la línea 293T, la cual es una línea de células de riñón

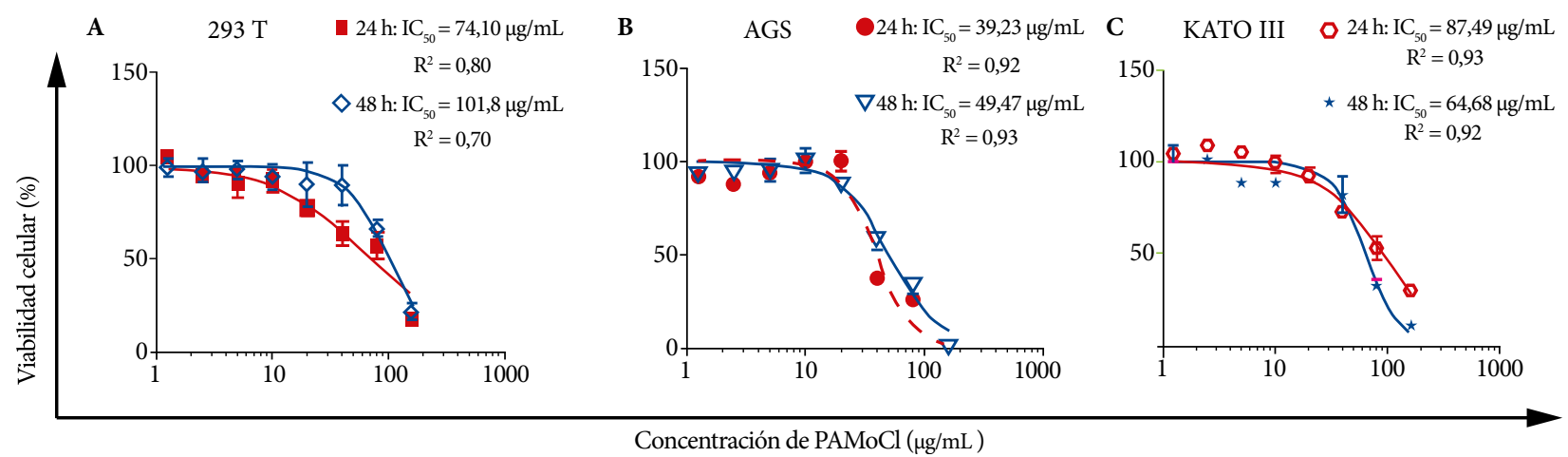

PAMoCl: Fracción clorofórmica del extracto metanólico de Piper aduncum

$\mathrm{IC}_{50}$ : Inhibición del crecimiento celular en un $50 \%$

$\mathrm{R}^{2}$ : Coeficiente de determinación del modelo de regresión no lineal

Figura 2. Efecto de la fracción clorofórmica del extracto metanólico de Piper aduncum (PAMoCl) en la viabilidad celular. Las líneas celulares 293T, AGS y KATO III fueron tratadas a diferentes concentraciones de PAMoCl $(1,25 ; 2,5 ; 5 ; 10 ; 20 ; 40 ; 80$ y $160 \mu \mathrm{g} / \mathrm{mL})$ durante 24 y 48 horas. Se muestran gráficas de $\mathrm{IC}_{50}$ que son curvas de viabilidad celular (\%) dependientes del $\log 10$ de la concentración de PAMoCl $(\mu \mathrm{g} / \mathrm{mL})$ para cada línea celular. En la parte superior derecha de cada gráfica se muestran los valores de $\mathrm{IC}_{50}$ a las 24 y 48 horas. 

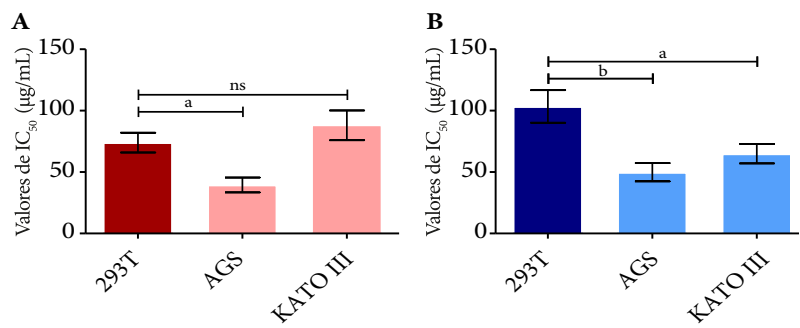

${ }^{\mathrm{a}} \mathrm{p}<0,05 ;{ }^{\mathrm{b}} \mathrm{p}<0,01 ;$ ns: no significativo

Figura 3. Comparación de los valores de inhibición del crecimiento celular en un $50 \%\left(\mathrm{IC}_{50}\right)$ para cada línea celular a las (A) 24 horas y (B) 48 horas

humano embrionario y fue usada como control de toxicidad. Esto demuestra que $\mathrm{PAMoCl}$ tiene mayor efecto en células de cáncer gástrico que en las no cancerígenas.

Diversos metabolitos encontrados en las plantas del género Piper han mostrado tener actividad biológica, especialmente los alcaloides. Por ejemplo, la piperina ha demostrado inhibir el crecimiento tumoral y la metástasis de células de cáncer de pulmón ${ }^{(16)}$. La pipernonalina muestra actividad frente a las células humanas de cáncer de próstata ${ }^{(17)}$. Las amidas también pueden inhibir el crecimiento en líneas celulares cancerosas ${ }^{(18)}$.

En este estudio se observó que el PAMoCl tiene un efecto dependiente de la concentración a nivel del ciclo celular, lo cual provoca la detención de las células tratadas en la fase G2/M. Este efecto fue observado tanto en las células AGS como en KATO III. Estos resultados coinciden con los reportados para metabolitos de otras plantas que han demostrado tener el mismo efecto en la fase G2/M, entre estos, la roscovitina (purinas) en cáncer de pulmón de células no pequeñas ${ }^{(19)}$, linfoma ${ }^{(20)}$ y cáncer de mama ${ }^{(21)}$, inhibían la expresión de las proteínas p53, CDK7, ciclina A, ciclina E y CDK2; sulforafano (isotiacianatos), a través del aumento de la expresión de la ciclina B1 y p21 ${ }^{(22)}$; quercetina (flavonoles) en células de hepatocarcinoma, mediante la sobreexpresión de p53, p21 y la disminución de la expresión de la ciclina D1, CDK2 y CDK7 ${ }^{(23)}$; y la berberina (alcaloides) en células de leucemia inhibe la expresión de ciclina B1 y el incremento de la expresión de Wee1 ${ }^{(24)}$.

$\mathrm{Al}$ igual que en este estudio, en el género Piper también existen varias especies cuyos metabolitos mostraron efecto en la fase G2/M, entre estos la piperina de $P$. nigrum y $P$. longum en células de osteosarcoma ${ }^{(25)}$, flavokawaina de P. methysticum ${ }^{(26)}$, hinokinina de $P$. cubeba ${ }^{(27)}$, hidroxichavicol de $P$. betle ${ }^{(28)}$ y la piperlongumina de P. longum L. mostraron disminución de la expresión de la ciclina D1 en células AGS ${ }^{(29)}$.

En el análisis fitoquímico se ha detectado la presencia de cuatro grupos de metabolitos en PAMoCl: grupos fenólicos

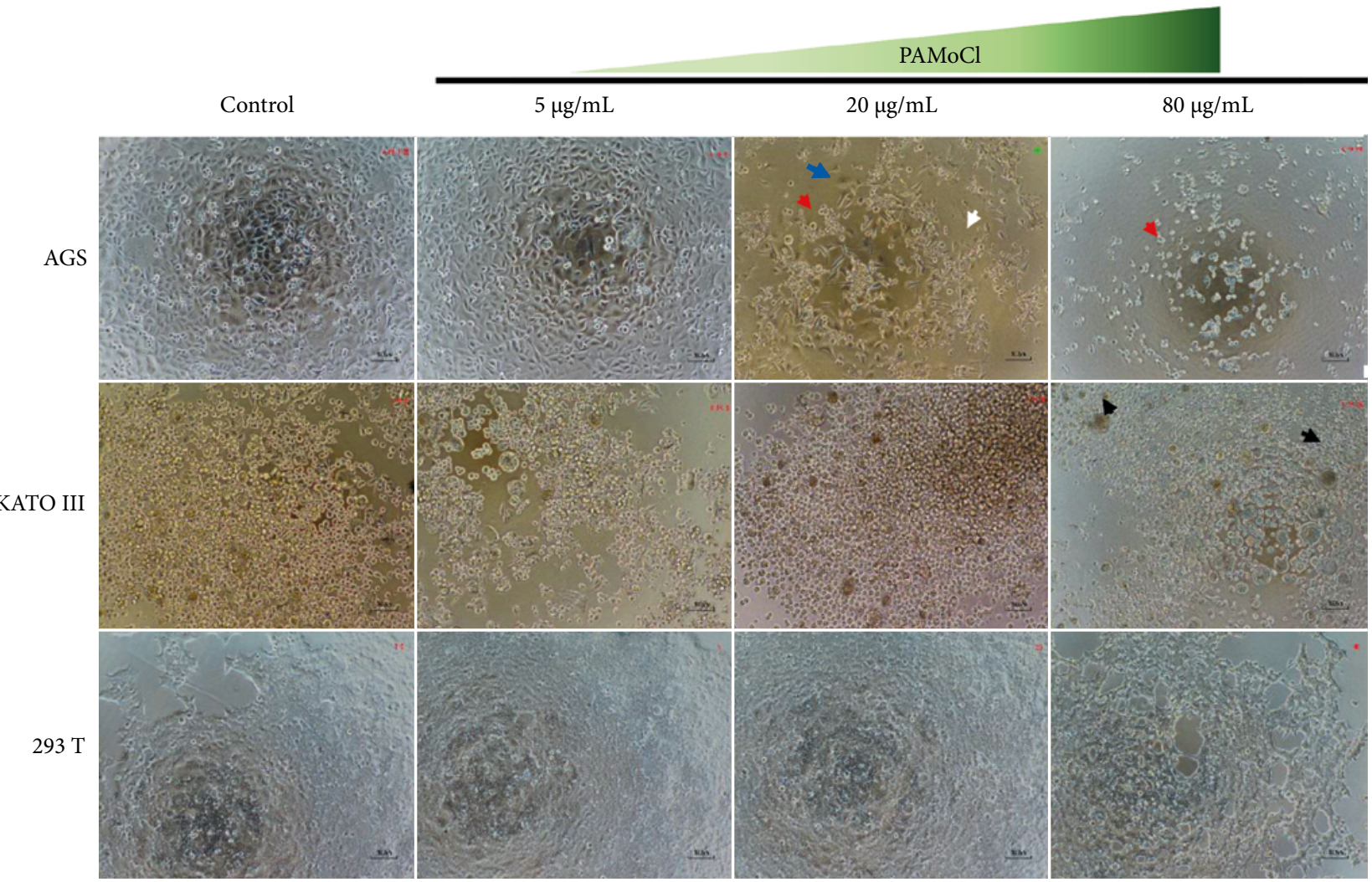

Figura 4. Efecto de la fracción clorofórmica del extracto metanólico de Piper aduncum a concentraciones de $5 \mu \mathrm{g} / \mathrm{mL}, 20 \mu \mathrm{g} / \mathrm{mL}$ y $80 \mu \mathrm{g} / \mathrm{mL}$ en la morfología de las líneas celulares de cáncer gástrico AGS, KATO III y de riñón humano 293T. También se muestra un grupo control de células sin tratamiento, pero con el vehículo (DMSO 0,5\%) para cada línea celular. A.T. 100X. Flecha roja: células resuspendidas; flecha azul: células adheridas, flecha blanca: célula contraídas; y flecha negra: células muertas 

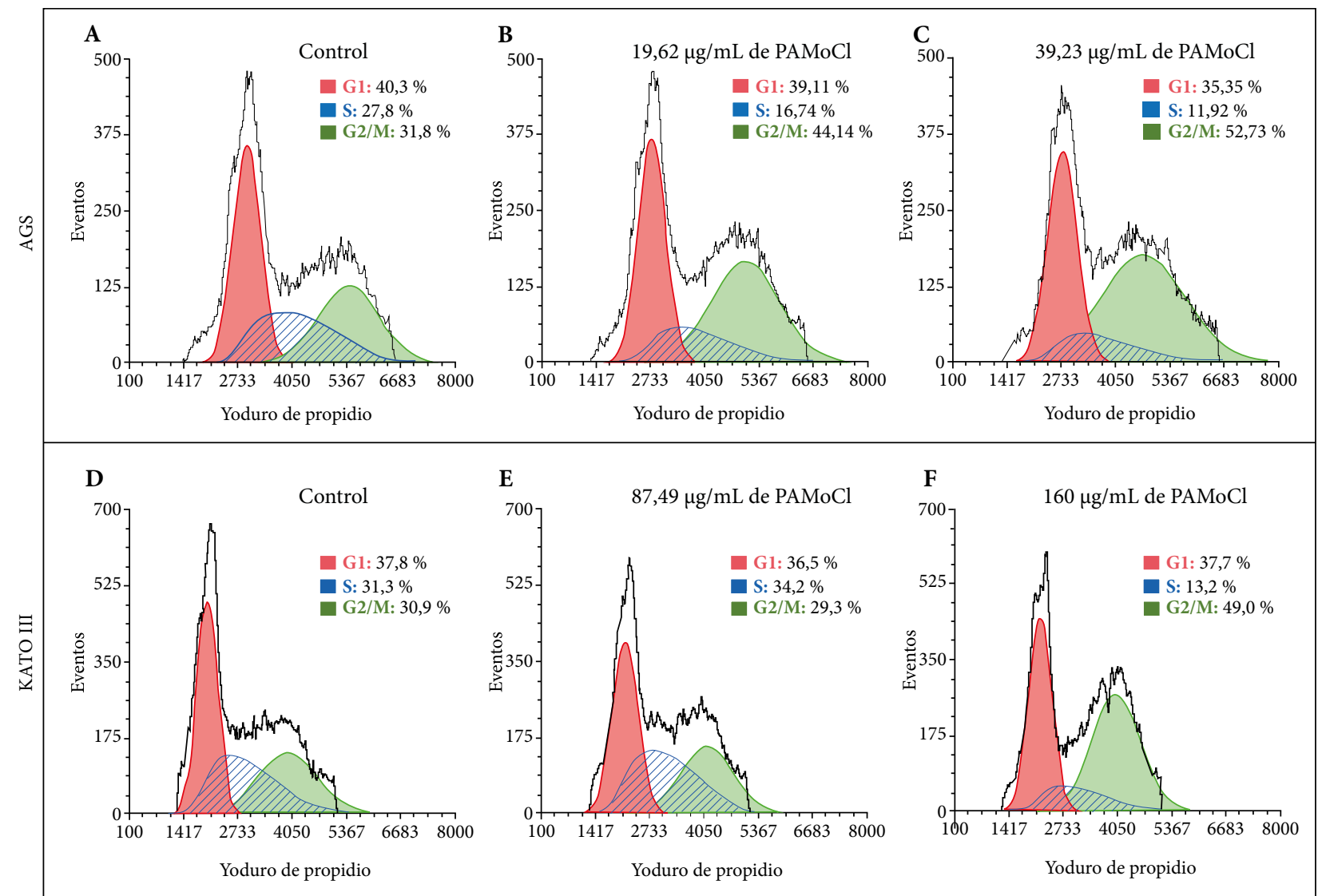

PAMoCl: Fracción clorofórmica del extracto metanólico de Piper aduncum

Figura 5. Análisis de citometría de flujo para el ciclo celular de las líneas celulares de cáncer gástrico AGS y KATO III tratadas con la fracción clorofórmica del extracto metanólico de Piper aduncum (PAMoCl). Se muestran histogramas que indican la cantidad de ADN marcado por yoduro de propidio. Considerándose tres grupos para cada línea celular: A) grupo control con células AGS sin PAMoCl pero con el vehículo; B) células AGS tratadas con 19,62 $\mu \mathrm{g} / \mathrm{mL}$ de PAMoCl; C) células AGS tratadas con 39,23 $\mu \mathrm{g} / \mathrm{mL}$ de PAMoCl; D) grupo control con células KATO III sin tratamiento, pero sí con el vehículo; E) células KATO III tratadas con $87,49 \mu \mathrm{g} / \mathrm{mL}$ de PAMoCl; F) células KATO III tratadas con $160 \mu \mathrm{g} / \mathrm{mL}$ de PAMoCl. Data cruda de citometría de flujo (curva negra), G1: Gap 1 (curva roja), S: síntesis (curva azul) y G2/M: Gap 2/mitosis (curva verde), fases del ciclo celular.

y derivados, flavonoides, antocianinas, triterpenoides y esteroides, por lo que consideramos importante profundizar en la identificación de los metabolitos secundarios utilizando técnicas analíticas, como la cromatografía, la espectroscopía infrarroja, la espectrometría de masas y la resonancia magnética nuclear que podrían permitirnos dilucidar la estructura química de los compuestos activos. Sin embargo, se debe tener en cuenta que existen limitaciones en este estudio, como el lugar y tiempo de colecta de la muestra, el método de extracción, entre otros, los cuales son factores que pueden generar variabilidad en la cantidad de metabolitos $y$, en consecuencia, su actividad biológica.

En conclusión, se afirma que PAMoCl contiene metabolitos secundarios con actividad citotóxica que tienen efecto en el ciclo celular y causan su detención en la fase G2/M en dos líneas celulares de cáncer gástrico tanto primario como metastásico. Los resultados de este estudio permitirán profundizar en la búsqueda de principios activos presentes en PA-
$\mathrm{MoCl}$ que tengan mayor eficacia en la eliminación de células de cáncer gástrico, pero con menor toxicidad en células sanas.

Agradecimientos: Al Dr. Juan Manuel Iglesias, jefe del laboratorio de Genética Molecular de la Universidad Científica del Sur, por la donación de la línea celular 293T usada en este estudio.

Contribuciones de los autores: AMH, STR y JAP participaron en la concepción y diseño del artículo, recolección de información y revisión crítica. AFY participó en la elaboración del extracto metanólico y la fracción clorofórmica de P. aduncum usado en este estudio. AMH y STR realizaron los experimentos, analizaron e interpretaron datos, y elaboraron la discusión. AMR apoyó en la interpretación de los resultados. Todos participaron en la redacción y aprobación de la versión final del artículo.

Fuentes de financiamiento: Este trabajo fue cofinanciado por el Consejo Nacional de Ciencia, Tecnologia e Innovacion Tecnologica (CONCYTEC) y la Universidad Científica del Sur, a través del proyecto «Evaluación del efecto de extractos y fracciones de tres plantas medicinales sobre células madre del cáncer gastrico», contrato $\mathrm{N}^{\circ} 134-2017$-FONDECYT.

Conflictos de interés: Los autores declaran no tener ningún conflicto de interés. 


\section{REFERENCIAS BIBLIOGRÁFICAS}

1. Bray F, Ferlay J, Soerjomataram I, Siegel RL, Torre LA, Jemal A. Global cancer statistics 2018: GLOBOCAN estimates of incidence and mortality worldwide for 36 cancers in 185 countries. CA Cancer J Clin. 2018;68(6):394-424. doi: 10.3322/caac.21492.

2. Torres-Román JS, Grados-Sánchez O. Cáncer gástrico en el Perú: una realidad susceptibilidad de cambio. Rev Gastroenterol del Perú [Internet]. 2015;35(3):276. Disponible en: http://www.revistagastroperu. com/index.php/rgp/article/view/118/115.

3. Singla AK, Garg A, Aggarwal D. Paclitaxel and its formulations. Int J Pharm. 2002;235(1-2):179-92. doi: 10.1016/s0378-5173(01)00986-3.

4. Thomas CJ, Rahier NJ, Hecht SM. Camptothecin: current perspectives. Bioorg Med Chem. 2004;12(7):1585-604. doi: 10.1016/j. bmc.2003.11.036.

5. Meresse P, Dechaux E, Monneret C, Bertounesque E. Etoposide: discovery and medicinal chemistry. Curr Med Chem. 2004;11(18):244366. doi: 10.2174/0929867043364531

6. Moore A, Pinkerton R. Vincristine: Can its therapeutic index be enhanced? Pediatr Blood Cancer. 2009;53(7):1180-7. doi: 10.1002/pbc.22161.

7. Lin Z-Y, Kuo C-H, Wu D-C, Chuang W-L. Anticancer effects of clinically acceptable colchicine concentrations on human gastric cancer cell lines. Kaohsiung J Med Sci. 2016;32(2):68-73. doi: 10.1016/j. kjms.2015.12.006.

8. Kumar N, Misra P, Dube A, Bhattacharya S, Dikshit M, Ranade S. Piper betle Linn. a maligned Pan-Asiatic plant with an array of pharmacological activities and prospects for drug discovery. Curr Sci. 2010;99(7):922-32. Disponible en: https://www.jstor.org/stable/24066069.

9. Wang YH, Morris-Natschke S, Yang J, Niu HM, Long CL, Lee KH. Anticancer principles from medicinal Piper (Hú Jiāo) plants. J Tradit Complement Med. 2014;4(1):8-16. doi: 10.4103/2225-4110.124811.

10. Herrera-Calderon O, Alvarado-Puray C, Arroyo-Acevedo J, Rojas-Armas J, Chumpitaz-Cerrate V, Hañari-Quispe R, et al. Phytochemical screening, total phenolic content, antioxidant, and cytotoxic activity of five peruvian plants on human tumor cell lines. Pharmacognosy Res. 2018;10(2);161-165. doi: 10.4103/pr.pr_109_17.

11. Amiel-Pérez J, Fukusaki A, Enciso N, Altamirano C, Herrera AM, Marcelo Á, et al. Interferencia de pigmentos vegetales al aplicar la técnica XTT a extractos de Buddleja globosa, Senecio tephrosiodes Turcz. Y Equisetum giganteum. Científica. 2016;13(1):9-26. doi: 10.21142/cient.v13i1.318.

12. Bladt S. Plant Drug Analysis: A thin layer chromatography atlas. Springer Science \& Business Media; 2009. doi: 10.1007/978-3-642-00574-9.

13. Lock OR. Invetigacion Fitoquimica, Metodos en el estudio de productos naturales. 1ra. edición. Lima: Pontificia Univ Catolica Peru; 2016.

14. Riss TL, Moravec RA, Niles AL, Duellman S, Benink HA, Worzella TJ, et al. Cell Viability Assays. Assay Guid Man [Internet]. 2004;(Md):125. Disponible en: http://www.ncbi.nlm.nih.gov/pubmed/23805433.

15. Crowley LC, Chojnowski G, Waterhouse NJ. Measuring the DNA content of cells in apoptosis and at different cell-cycle stages by propidium iodide staining and flow cytometry. Cold Spring Harb Protoc. 2016;2016(10):pdb-prot087247. doi: 10.1101/pdb.prot087247.

16. Lai L, Fu Q, Liu Y, Jiang K, Guo Q, Chen Q, et al. Piperine suppresses tumor growth and metastasis in vitro and in vivo in a $4 \mathrm{~T} 1$ murine breast cancer model. Acta Pharmacol Sin. 2012;523. doi: 10.1038/aps.2011.209.
17. Lee W, Kim K-Y, Yu S-N, Kim S-H, Chun S-S, Ji J-H, et al. Pipernonaline from Piper longum Linn. induces ROS-mediated apoptosis in human prostate cancer PC-3 cells. Biochem Biophys Res Commun. 2013;430(1):406-12. doi: 10.1016/j.bbrc.2012.11.030.

18. Bezerra DP, Pessoa C, de Moraes MO, Silveira ER, Lima MAS, Elmiro FJM, et al. Antiproliferative effects of two amides, piperine and piplartine, from Piper species. Zeitschrift für Naturforsch C. 2005;60(7-8):539-43. doi: 10.1515/znc-2005-7-805.

19. Zhang F, Zhang T, Gu Z-P, Zhou Y-A, Han Y, Li X-F, et al. Enhancement of radiosensitivity by roscovitine pretreatment in human non-small cell lung cancer A549 cells. J Radiat Res. 2008;49(5):541-8. doi: 10.1269/jrr.08024.

20. Lacrima K, Rinaldi A, Vignati S, Martin V, Tibiletti MG, Gaidano G, et al. Cyclin-dependent kinase inhibitor seliciclib shows in vitro activity in diffuse large B-cell lymphomas. Leuk Lymphoma. 2007;48(1):15867. doi: $10.1080 / 10428190601026562$.

21. Węsierska冈Gądek J, Gritsch D, Zulehner N, Komina O, Maurer M. Interference with ER $\unrhd$ a enhances the therapeutic efficacy of the selective CDK inhibitor roscovitine towards ER冈positive breast cancer cells. J Cell Biochem. 2011;112(4):1103-17. doi: 10.1002/jcb.23024.

22. Parnaud G, Li P, Cassar G, Rouimi P, Tulliez J, Combaret L, et al. Mechanism of sulforaphane-induced cell cycle arrest and apoptosis in human colon cancer cells. Nutr Cancer. 2004;48(2):198-206. doi: 10.1207/s15327914nc4802_10.

23. Li Y, Duan S, Jia H, Bai C, Zhang L, Wang Z. Flavonoids from tartary buckwheat induce G2/M cell cycle arrest and apoptosis in human hepatoma HepG2 cells. Acta Biochim Biophys Sin. 2014;46(6):460-70. doi: 10.1093/abbs/gmu023.

24. Khan M, Giessrigl B, Vonach C, Madlener S, Prinz S, Herbaceck I, et al. Berberine and a Berberis lycium extract inactivate $\mathrm{Cdc} 25 \mathrm{~A}$ and induce a-tubulin acetylation that correlate with HL-60 cell cycle inhibition and apoptosis. Mutat Res Mol Mech Mutagen. 2010;683(1-2):123-30. doi: 10.1016/j.mrfmmm.2009.11.001.

25. Zhang J, Zhu X, Li H, Li B, Sun L, Xie T, et al. Piperine inhibits proliferation of human osteosarcoma cells via G2/M phase arrest and metastasis by suppressing MMP-2/-9 expression. Int Immunopharmacol. 2015;24(1):50-8. doi: 10.1016/j.intimp.2014.11.012.

26. JiT,Lin C,Krill LS, Eskander R, Guo Y,ZiX, et al. Flavokawain B, akava chalcone, inhibits growth of human osteosarcoma cells through G2/M cell cycle arrest and apoptosis. Mol Cancer. 2013;12(1):55. doi: 10.1186/1476-4598-12-55.

27. Cunha NL, Teixeira GM, Martins TD, Souza AR, Oliveira PF, Símaro GV, et al. (-)-Hinokinin Induces G2/M Arrest and Contributes to the Antiproliferative Effects of Doxorubicin in Breast Cancer Cells. Planta Med. 2016;82(06):530-8. doi: 10.1055/s-0042-101761.

28. Guha Majumdar A, Subramanian M. Hydroxychavicol from Piper betle induces apoptosis, cell cycle arrest, and inhibits epithelial-mesenchymal transition in pancreatic cancer cells. Biochem Pharmacol. 2019;166:274-291. doi: 10.1016/j.bcp.2019.05.025.

29. Song B, Zhan H, Bian Q, Gu J. Piperlongumine inhibits gastric cancer cells via suppression of the JAK1, 2/STAT3 signaling pathway. Mol Med Rep. 2016;13(5):4475-80. doi: 10.3892/mmr.2016.5091. 